Chapter 9

\title{
Components of Natural Photosynthetic Apparatus in Solar Cells
}

\author{
Roman A. Voloshin, Margarita V. Rodionova, \\ Sergey K. Zharmukhamedov, Harvey J.M. Hou, \\ Jian-Ren Shen and Suleyman I. Allakhverdiev \\ Additional information is available at the end of the chapter
}

http://dx.doi.org/10.5772/62238

\begin{abstract}
Oxygenic photosynthesis is a process of light energy conversion into the chemical energy using water and carbon dioxide. The efficiency of energy conversion in the primary processes of photosynthesis is close to $100 \%$. Therefore, for many years, photosynthesis has attracted the attention of researchers as the most efficient and ecofriendly pathway of solar energy conversion for alternative energy systems. The recent advances in the design of optimal solar cells include the creation of converters, in which thylakoid membranes, photosystems and whole cells of cyanobacteria immobilized on nanostructured electrode are used. As the mechanism of solar energy conversion in photosynthesis is sustainable and environmentally safe, it has a great potential as an example of renewable energy device. Application of pigments such as $\mathrm{Chl} f$ and $\mathrm{Chl} d$ will extend the spectral diapason of light transforming systems allow to absorb the farred and near infra-red photons of the spectrum (in the range 700-750 nm). This article presents the recent achievements and challenges in the area of solar cells based on photosynthetic systems.
\end{abstract}

Keywords: Solar cell, Thylakoids, Photosystem I, Photosystem II, Sensibilizator

\section{Introduction}

The energy crisis and environmental problems are among the most important challenges for humanity to solve in the twenty-first century. Many of the actual investigations are focused on the development of renewable, sustainable and eco-friendly energy sources [1]. 
Nowadays, the available sources of renewable energy, including solar, wind, rain energy, energy of waves and geothermal heat, could generate only approximately $16 \%$ of the energy used [2]. Global energy consumption is about 17 TW according to the information of the year 2014 [3]. The flux density of sunlight emission near the ground surface is about $100 \mathrm{PW}$, which exceeds 5000 times our current needs [4]. Even though the solar period and the presence of clouds are taken into account, the sun is the extremely attractive source of energy, given we know how to extract it. Thus, sunlight is the most accessible and reliable source among the other renewable energy sources.

Photosynthesis is one of the main pathways of solar energy conversion, performed by higher plants, microalgae and some bacteria. Over 2.5 billion years, plant photosynthesis has evolved to convert solar energy into the chemical energy using only water as electron donor and proton source. This photosynthesis realises oxygen and is called oxygenic. Water, carbon dioxide and light are necessary for oxygenic phototrophic organisms to produce carbohydrates. The lightdependent reaction of photosynthesis takes place in the thylakoid membrane of photosynthetic organisms. The thylakoid membrane involves two photosystems (PSI and PSII), cytochrome $\mathrm{b}_{6} \mathrm{f}$ complex and other protein complexes embedded in a lipid bilayer. PSI and PSII can capture sunlight and create an electron-hole pair [5,6]. The latter process operates with a quantum yield closer to $100 \%$. Water, one of the most abundant substances on Earth, is the donor of electron for PSII [2].

For several decades, photovoltaic semiconductor devices have also been developed to generate electric power by converting sunlight directly into the electricity. The coefficient of efficiency of the light energy conversion into the electric current produced by commercial silicon photovoltaic cells is typically less than $20 \%$ [7]. Unfortunately, exhaustible materials and components used in photovoltaic systems cannot be fully recycled. Considering that the efficiency of energy conversion in the primary processes of photosynthesis is close to $100 \%$, it is reasonable to use this natural process for energy conversion applications.

Recently, after critical analysis of the photosynthetic and photovoltaic energy conversion mechanisms, experts in the area of artificial photosynthesis concluded that it is difficult to compare the conversion efficiency of the current photovoltaic cells with that of the living photosynthesizing cells, as they are completely different systems [7]. The efficiency of photovoltaic cells can be calculated by dividing the cell's output power by the total solar radiation spectrum. However, the storage and energy transfer are not considered by this approach. Photovoltaic batteries, in which energy is stored, have high production cost and the expenses required for the maintenance of such systems. Photosynthesis stores solar energy in the form of chemical energy, which can further be converted into electrical energy [2].

\section{Photosynthesis}

Photosynthesis is the process of conversion of the sunlight energy into chemical energy of various organic compounds, which is carried out by photosynthesizing organisms. Photosynthesis serves as the primary source of energy for all kinds of life on Earth. Photosynthetic 
organisms are sources of energy and essential metabolites for heterotrophic organisms [8, 9]. This process proceeds in two stages: the light stage of the light absorption by photosynthetic pigments and the formation of adenosine triphosphate (ATP) and nicotinamide adenine dinucleotide phosphate (NADPH) and the dark stage when the biosynthesis of carbohydrates occurs. During the dark stage, carbon dioxide $\left(\mathrm{CO}_{2}\right)$ acts as a carbon substrate, NADPH molecule is a proton source, and ATP molecule is a source of energy. The electron transport chain (ETC) is an essential element of the light stage of photosynthesis. An electron is transferred to the $\mathrm{NADP}^{+}$molecule through ETC, which leads to the reduction of the $\mathrm{NADP}^{+}$to NADPH. An external source of electrons is required to reduce the oxidized pigment molecule. The type of photosynthesis using water as an electron source is called oxygenic one, since molecular oxygen is a by-product of the water decomposition [10].

The oxygenic photosynthesis is explicit in all plants, microalgae and cyanobacteria. It is the key source of oxygen in the atmosphere.

The oxygenic photosynthesis could be summarized through the following general equation:

$$
\mathrm{CO}_{2}+\mathrm{H}_{2} \mathrm{O} \stackrel{\mathrm{h} v}{\rightarrow}\left[\mathrm{CH}_{2} \mathrm{O}\right]+\mathrm{O}_{2}
$$

Light stage processes of the oxygenic photosynthesis occur in membrane structures called thylakoids. In eukaryotic cells of green plants, thylakoids are localized in specific photosynthetic organelles - chloroplasts. The space limited by chloroplast membrane is determined as stroma, and the space inside the thylakoid is determined as lumen. Thus, one side of the thylakoid membrane faces the stroma, and the other side faces the lumen. In cyanobacteria cells, thylakoids are located directly in the cytoplasm [11].

Light energy is not immediately converted into ATP energy. In fact, it is initially stored in the form of a transmembrane electrochemical potential formed due to the proton transfer by lipophilic transporters through the thylakoid membrane from the stroma to the lumen. As a result, the lumen becomes acidic and the stroma is alkalized. Due to the energy of the created potential difference $\left(\Delta \mu \mathrm{H}^{+}\right)$, the enzyme ATP-synthase embedded in the thylakoid membrane starts to function [12].

The light stage of photosynthesis is a sequence of enzymatic reactions. There are four transmembrane protein enzymes that catalyse these reactions in higher plants: PSI, PSII, cytochrome $\mathrm{b}_{6} \mathrm{f}$ complex $\left(\mathrm{Cyt}_{\mathrm{b}_{6}} \mathrm{f}\right)$ and ATP-synthase [11]. PSII catalyses the electron transfer reaction from the water molecule to plastoquinone (PQ). The Cyt $b_{6} f$ is involved in the oxidation of plastoquinole and reduction of plastocyanin $(\mathrm{Pc})$. It mediates the transfer of electrons from PSII to PSI as well as of protons from stroma to lumen [12]. PSI catalyses the oxidation of lipophilic electron carrier plastocyanine, and the ferredoxin $(\mathrm{Fd})$ reduction. The enzyme ferredoxin: $\mathrm{NADP}^{+}$oxidoreductase (FNR) catalyses the $\mathrm{NADP}^{+}$reduction due to the electrons from the reduced Fd (Fig. 1). 


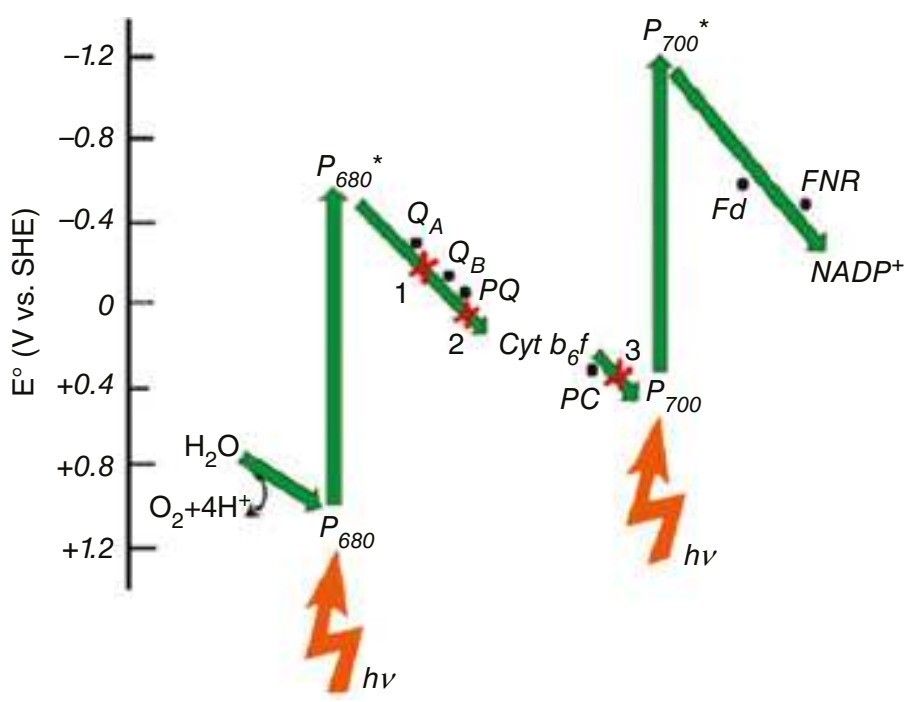

Figure 1 The scheme of the non-cyclic electron transport pathway in thylakoids of higher plants and the redox potentials of the components of electron transport chain. $\mathrm{P}_{680}$ - primary electron donor in photosystem II; $\mathrm{P}_{680}{ }^{*}-$ singlet exited state of $\mathrm{P}_{680} ; \mathrm{P}_{700}$ - primary electron donor in photosystem I; $\mathrm{P}_{700}{ }^{*}$ - singlet exited state of $\mathrm{P}_{700} ; Q_{A}$ and $Q_{B}$ are primary and secondary quinone electron acceptors, respectively. Red crosses represent reactions that can be inhibited by a) 3(3,4-dichlorophenyl)-1,1-dimethylurea (DCMU); b) dibromothymoquinone (DBMIB); c) potassium cyanide (KCN) (adapted from [2]).

The primary charge separation involving photosynthetic pigments occurs in the special part of photosystem complex called photosynthetic reaction centre (RC). In the RC, the primary electron donor is at the inner lumenal side of thylakoid membrane, whereas the primary electron acceptor is closer to the outer stromal side. Thus, an electron from the molecules of the primary electron donor moves onto the opposite side of the thylakoid membrane [12].

The ETC is activated by light. First, photons are absorbed by the pigments of special antenna complex. Then, the energy of the light quanta is transferred to RC by hopping mechanism [13]. In the RC, a special pair of chlorophyll is excited by the photon energy. Chlorophyll is the pigment molecule that can be excited by light of a certain wavelength (Fig. 2). The basis of the chlorophyll structure is a heterocyclic ring consisting of four pyrrole rings connected by methine bridges [14]. Four nitrogen atoms within the chlorine ring are associated with magnesium ion $\left(\mathrm{Mg}^{2+}\right)$. A long hydrophobic phytol tail is attached to the fourth pyrrole ring, whereas a pigment molecule is correctly oriented in the membrane. In nature, there are two widespread forms of chlorophyll: $\mathrm{Chl} a$ and $\mathrm{Chl} b$.

$\mathrm{Chl} a$ serves as the primary electron donor in the $\mathrm{RC}$, and $\mathrm{Chl} b$ is the accessory pigment of the antenna complexes. A free $\mathrm{Chl} a$ molecule absorbs light preferably in the wavelength ranges of 400-500 nm and 600-700 nm. Due to the usage of other pigments, for example, carotenoids, the absorption spectrum of the photosystems is much broader [16]. In addition to Chl $a$ and $\mathrm{Chl} b$, other forms of chlorophyll, $\mathrm{Chl} d$ and $\mathrm{Chl} f$, could also be found in antenna complexes 


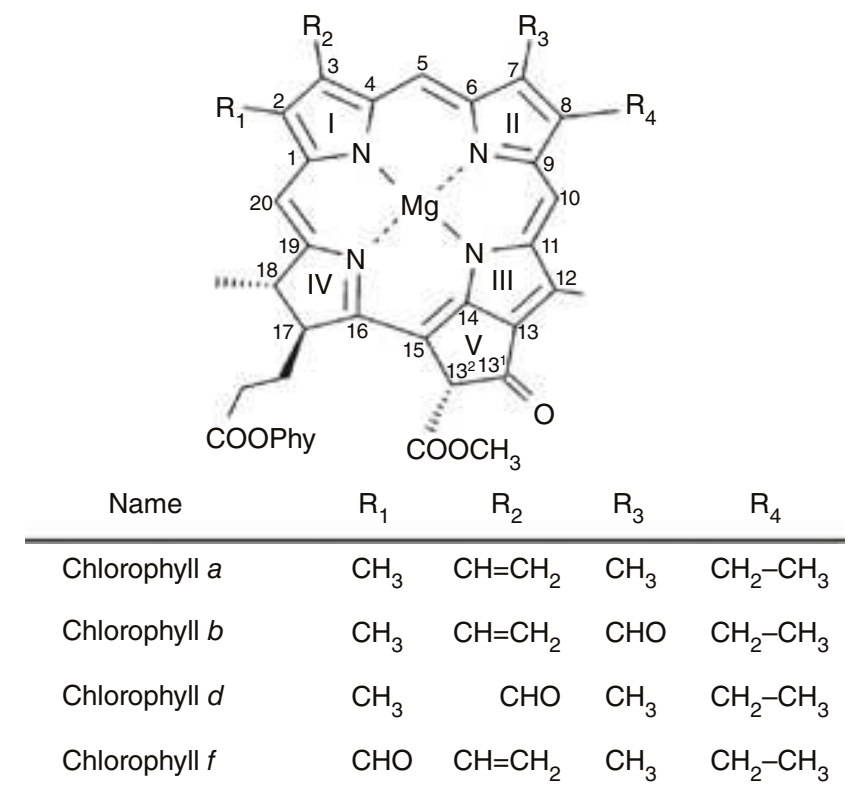

Figure 2 The structural formula of chlorophylls: Chl $a, \mathrm{Chl} b, \mathrm{Chl} d$, and $\mathrm{Chl} f$ (adapted from [15]).

of phototrophic organisms, such as cyanobacteria. Also Chl $d$ can be found in the photosynthetic RC $[17,18]$. The chemical difference among the Chl $b, \mathrm{Chl} d, \operatorname{Chl} f$ and the Chl $a$ is that methyl or vinyl group is substituted by formyl one. The chlorophylls also differ from each other in their absorption spectra. More specifically, the long-wavelength maximum in the absorption spectrum of $\mathrm{Chl} d$ and $\mathrm{Chl} f$ markedly shifts towards longer wavelengths compared to that of the Chl $a$ (shift up to $40 \mathrm{~nm}$ ). The energy region (i.e., 380-710 nm) consists of photosynthetically active radiations that constitute about $40 \%$ of the total solar radiation reaching the Earth's surface [19]. However, further expansion in the region ranging from 700 to $750 \mathrm{~nm}$ leads to the increase in the overall energy conversion intensity by about $19 \%$ [20].

\section{Solar cells}

Solar cells are used to convert solar energy into electrical energy. The development of effective and inexpensive solar cells is of particular interest because of the importance of alternate energy sources. Currently, there are many different types of solar energy converters. The solar cells, or photoelements, are devices that can convert solar energy into usable electrical energy. They are divided into two types: regenerative cells and photosynthetic cells [21]. In the regenerative cells, the sunlight energy is converted into electricity. This process is unaccompanied by any subsequent chemical reactions. Sometimes, such cells are called photobioelectrochemical cells. In photosynthetic cells, the sunlight energy is converted to the molecular 
fuel energy, for example, that of hydrogen [20-23]. Photosynthetic cells based on biological objects such as isolated photosystems [22] or the whole bacterial cells [23] are called photobiochemical fuel cells. This article focuses generally on the regenerative solar cells.

\subsection{Operating of solar cells}

The main steps can be identified for all types of solar cells [24]:

1. Absorption of light by photoactive component.

Photoactive component is the substance that absorbs photons inside the solar cell. A semiconductor acts as a photoactive component in conventional photovoltaic solar cells; while an organic pigment (photosensitizer molecule) serves as a photoactive component in dye-sensitized solar cells. Absorption of a photon leads to certain changes in the energy of the photosensitizer molecule, which is necessary for the further generation of current or the synthesis of molecular hydrogen [20].

2. The charge separation.

In photoelements using plant or bacterial photosystems, charge separation occurs due to a series of redox reactions. After the absorption of incident photon energy by special pigment molecule, a primary electron donor, a charge separation between primary electron donor and primary electron acceptor occurs. Then, the molecule of the primary donor is reduced by electrons from the secondary one and electron from the primary acceptor is transferred into ETC components. This stage is termed as charge stabilization. Some voltage is generated in the photoelement as a result of these processes.

3. The transfer of electrons to an external circuit for biofuel generation.

For the elements acting as a photoelectric converter (regenerative cells), this step implies an electron transfer to the electrode, and further to an external circuit. For photosynthetic cells, charge separation leads to the activation of the sequence of redox reactions, resulting in the formation of molecular hydrogen [20].

\subsection{The coefficient of efficiency of regenerative solar cells}

One of the basic estimation parameters of regenerative solar cells is the coefficient of efficiency. The efficiency of solar cell energy conversion is determined as a ratio of power electrical output to the intensity of incident light.

$$
\eta=\frac{P_{\text {ell }}}{J_{\text {light }}}
$$

Some conditions of accepted standard tests of solar cells are: air mass of AM 1.5, light intensity of $1 \mathrm{~kW} / \mathrm{m}^{2}$ with a temperature of $298 \mathrm{~K}$. Air mass is a ratio of the way, where sunlight passes in the atmosphere, to the thickness of the atmosphere; the value of AM 1.5 means that the sun is set at an angle of $48^{\circ}$ to its position in zenith point [4], which is explained in Figure 3. 


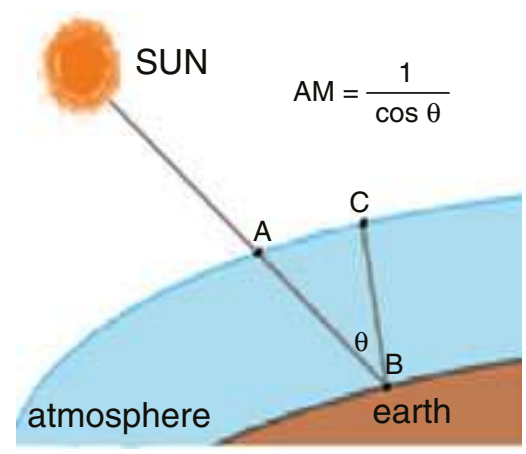

Figure 3 Explanation of air mass (AM) notion.

Traditionally, the efficiency coefficient of photoelement is defined by means of voltammetric methods [25]. The controlled voltage source is attached to the solar cell. Then, the values of the current passing through the photoelement under different values of voltage are obtained using galvanometer. Current dependence on voltage received is called current-voltage characteristic (I-V). A typical I-V curve of photoelement in the darkness and in the light is presented in Figure 4. In the darkness, the photoelement acts as a diode in reverse bias, almost no current flows through the cell in conditions of increasing voltage - there is no free charge carrier. Once the external voltage becomes higher than the potentials, which are holding the electrons in atoms, a sharp increase of the current occurs. This phenomenon is called breakdown. In the light of sufficient intensity, there will be the current in the circuit even under the voltage equal to zero: at the light, solar cell generates photovoltage. The direction of this current will be the opposite to that in case of breakdown. While the external voltage acting in the reverse direction increases, the photocurrent will decrease until it reaches value of zero. Then, there will be the situation similar to the breakdown: the reverse current significantly increases.

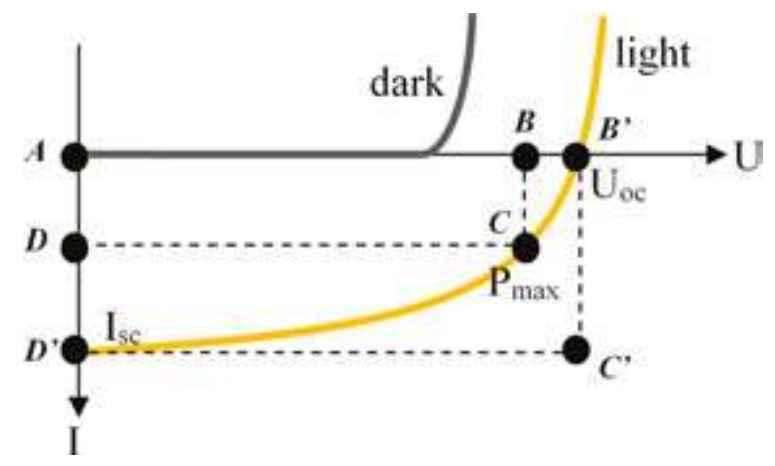

Figure 4 Typical I-V curve of photoelement. 
On the I-V curve, it is possible to determine four parameters of the cell: short-circuit current, open-circuit voltage, values of current and voltage defining maximum power generated by the cell [25].

Short-circuit current $I_{\mathrm{sc}}$ (the current at an external voltage equal to zero) is the point of I-V intersection with the vertical axis. Open-circuit voltage $V_{\text {oc }}$ is the voltage equal in absolute value to photovoltage and opposite to it in sign: if it is applied to the cell, no current flows. Opencircuit voltage is determined by the I-V curve intersection with the axis of abscissa. Current power generated on the cell is determined by the voltage $V$ and current $I$.

$$
P_{\text {ell }}=I \cdot V
$$

There is a point on the $\mathrm{I}-\mathrm{V}$ curve, where the value $P$ reaches its maximum, $P_{\max }$. The product of $I_{\mathrm{sc}}$ and $V_{\mathrm{oc}}$ presents the value proportionate to an area of rectangle $\mathrm{AB}^{\prime} \mathrm{C}^{\prime} \mathrm{D}^{\prime}$ (Fig. 4). The ratio of maximum power $P_{\max }$ corresponded to the area of rectangle ABCD, to the product of $I_{\mathrm{sc}}$ by $V_{\text {oc }}$ is called fill factor.

$$
F F=\frac{S_{A B C D}}{S_{A B^{\prime} C^{\prime} D^{\prime}}}=\frac{P_{\max }}{I_{s c} \cdot V_{o c}}
$$

Thereby, the maximum coefficient of efficiency could be expressed by the following equation:

$$
\eta_{\max }=\frac{P_{\max }}{J_{\text {light }}}=\frac{I_{s c} \cdot V_{o c} \cdot F F}{J_{\text {light }}}
$$

\section{The use of components/systems of the photosynthetic apparatus to generate electricity}

Nowadays, solar cells containing mono- and polycrystalline silicon as inorganic semiconductors are used for commercial applications in small devices, such as solar panels on roofs, pocket calculators, water pumps, and also in space technologies. Common traditional solar batteries can use less than $20 \%$ of the incident solar light [4]. Production of silicon solar cells requires energy-intensive processes, high temperatures $\left(400-1400{ }^{\circ} \mathrm{C}\right)$ and pure vacuum conditions, which results in high cost of such cells [24]. In contrast, production of solar cells based on biological photoactive components does not require these conditions. It suggests that biological-based solar cells are less expensive. The main disadvantage is the fact that they do not reach the efficiency of the inorganic solar cells [21, 24].

In recent researches, the thylakoid membrane and isolated PSI and PSII have been used in solar cells [26-28] and in optoelectronic devices by immobilizing these photoactive components directly onto the electrode surface [29-31] or via linker molecule [32-39]. 


\subsection{Thylakoids as photobiocatalysts}

Thylakoid membranes can be isolated from plant leaves and immobilized on the electrode surface to generate a photocurrent. A team of researchers led by Robert Carpentier [40] has been the first to begin using thylakoid membranes isolated from spinach leaves as a photosensitizer. In their work, a platinum electrode was used as a final acceptor. Studies were carried out in the light and in the dark, in the presence and in the absence of potassium ferrocyanide as a mediator. Native thylakoids generated a photocurrent up to 6-9 $\mu \mathrm{A}$ without a mediator, and four times more current in the presence of potassium ferrocyanide. This study has shown that the photocurrent generation without any mediators is associated with direct electron transfer from the membrane proteins to the electrode surface or through the molecules in the electrolyte that can function as mediators. Oxygen capable of producing the superoxide radical may be viewed as a mediator. In 2011, Bedford et al. [41] immobilized thylakoids on conductive nanofibers, using the electrospinning technique. The maximum electric power generated by the cell surface was $24 \mathrm{~mW} / \mathrm{cm}^{2}$ upon illumination by red light with a wavelength of $625 \mathrm{~nm}$.

It is possible to create a stable solar cell by combining the photosynthetic anode and biocatalytic cathode. There is an idea to use photosynthetic organisms/organelle/photosystems for the water oxidation at the anode and the conversion of oxygen into water at the cathode.

Calkins et al. [32] created solar cells using thylakoids isolated from spinach. Thylakoids were immobilized on the anode modified with multi-walled carbon nanotubes (MWCNT). Glass electrode modified by laccase/MWCNT system was used as the cathode (Fig. 5a). The study has demonstrated a maximum current density of $68 \mathrm{~mA} / \mathrm{cm}^{2}$ and a maximum power density of $5.3 \mathrm{~mW} / \mathrm{cm}^{2}$ (Fig. 5b). Composite electrode based on thylakoid/MWCNT produced a current density of $38 \mathrm{~mA} / \mathrm{cm}^{2}$ that is by two orders higher than predicted. The fact that the transmembrane chlorophyll-protein complexes remain in their native state during the isolation process is the main advantage of the usage of membrane thylakoids for photocurrent. This may lead to greater stability and greater power output as compared to the results that can be achieved by using isolated chlorophyll-protein complexes or RCs.

\subsection{Photosystem I as photobiocatalyst}

Besides the thylakoid membrane preparations, some researchers have conducted studies of photocurrent generating using cells based on isolated photosystems. There are two major benefits of using photosystems as a photosensitizers compared to thylakoids [20]:

a. There is less influence exerted by the other redox systems on the electron transfer in the photosystem chain.

b. RCs are closer to the electrode; it facilitates direct electron transfer to the electrode.

Fourmond et al. [42] developed a photobioelectrochemical system with PSI as the main photocatalytic subunit, cytochrome $\mathrm{C}_{6}$ and ferredoxin as electron carriers and FNR as an electron acceptor (Fig. 1). They used a gold electrode in the experiment. In an earlier investigation, Frolov et al. [43] created a photobioelectrochemical cell that could generate a voltage of $0.498 \pm 0.02 \mathrm{~V}$. They used the PSI preparations isolated from the cyanobacteria Synechocystis 

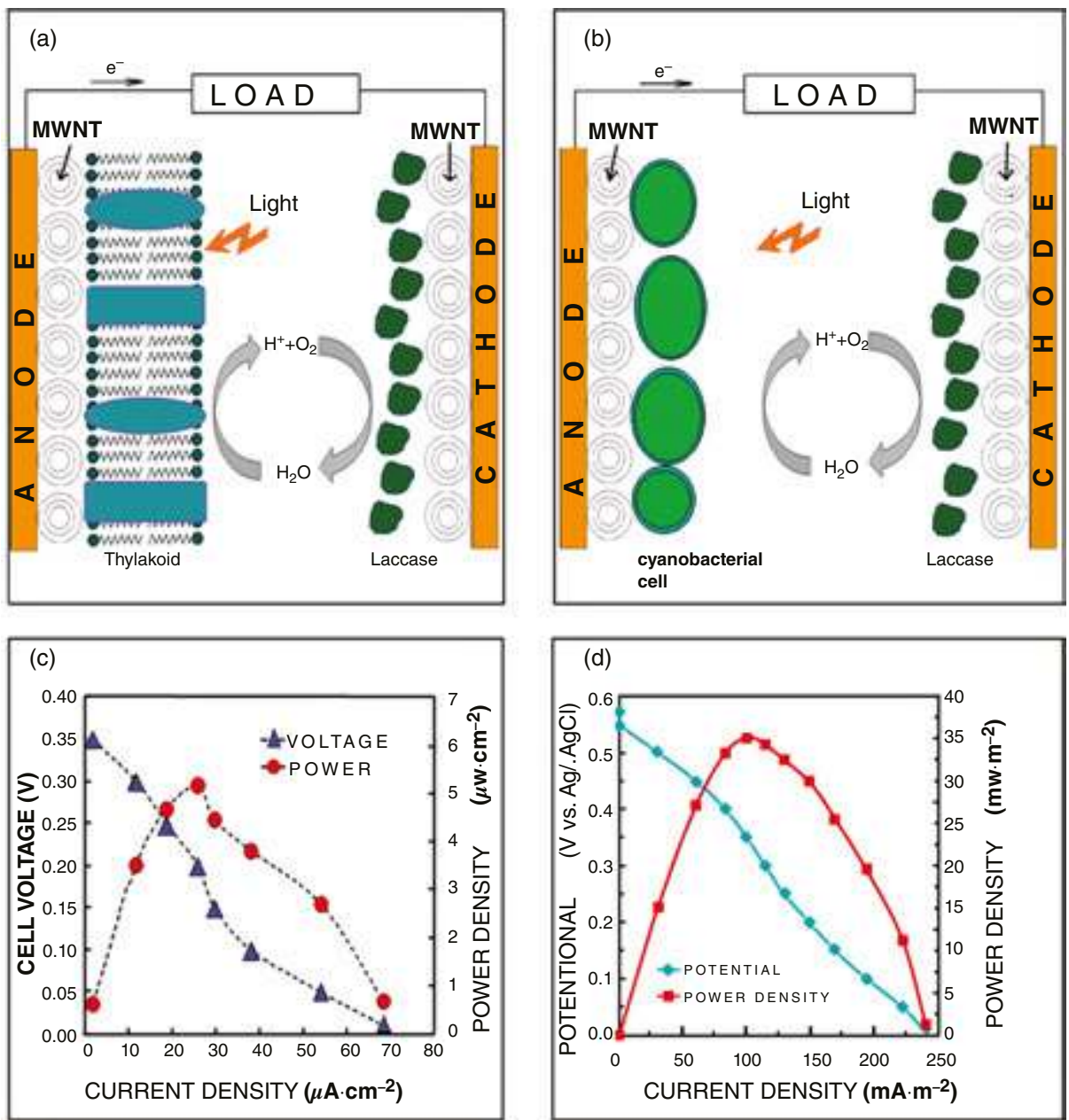

Figure 5 Schematic representation of the functioning photobioelectrochemical cells based on, a) the thylakoid/ MWCNT; b) cyanobacteria Nostoc/MWCNT; c) and d) the dependences of the voltage and the flux density of the received energy on the current density for each of the cells shown (adapted from [20,32]).

sp. PCC 6803. These systems are more stable than plant systems due to the antenna pigment molecule's integration into the core subunits. More specifically, unlike plant systems, the antenna pigments are associated only with chlorophyll-protein complex attached to core subunits. Surfactant peptides necessary for the stabilization of other plant and bacterial RCs were not required to stabilize such PSI. In their work, another important factor was the mutation-based replacement of specific amino acids of the PSI by cysteines. Properly oriented stable monolayer of PSI was formed through the formation of Au-S bonds between the thiol group of cysteine and purified hydrophilic gold surface. The procedure for creating the 
corresponding gold electrode included thermal treatment at $350{ }^{\circ} \mathrm{C}$. In studies carried out by Das et al [24], mutation-modified PSI complexes were attached to the gold electrode by $\mathrm{Ni}^{2+}-$ nitrilotriacetic acid $\left(\mathrm{Ni}^{2+}\right.$-NTA). In these complexes, native subunit PsaD was replaced by PsaD$\mathrm{His}_{6}$ one (Fig. 6a).
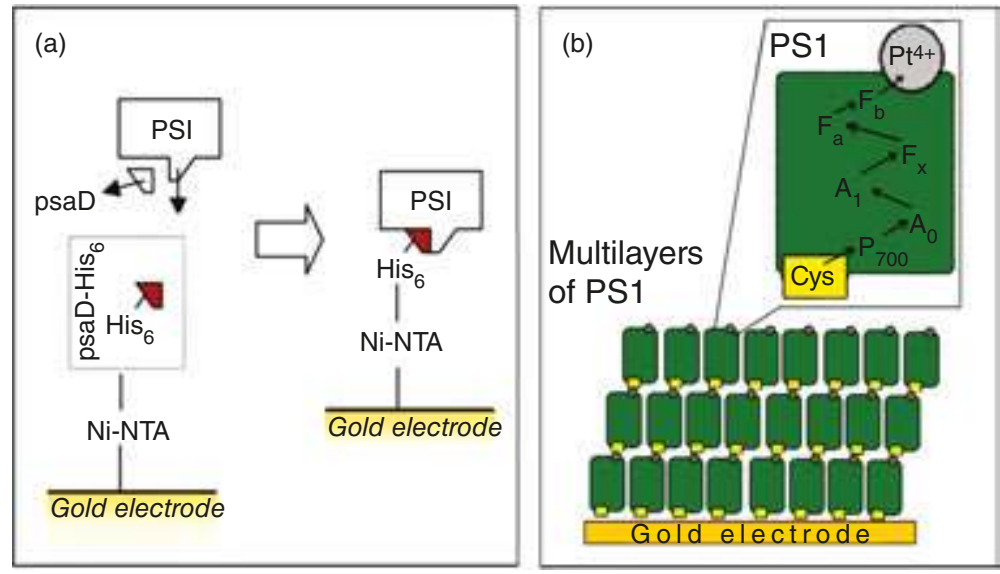

Figure 6 Models used for immobilizing photosystem I on the electrode. a) Native PsaD subunit of PSI replaced by PsaD-His, which clings to the histidine tag, and the entire structure is associated with the gold electrode through a $\mathrm{Ni}^{2+}$-NTA (adapted from $[20,24]$ ). b) The scheme of the cysteine mutants of the PSI with Pt ions and the multilayer structure of such PSI on a gold substrate (adapted from [20, 45]).

In another study, Faulkner et al. [44] reported a fast way to create a dense monolayer of PSI isolated from spinach leaves on a gold electrode. This method of the monolayer creation requiring vacuum conditions was 80 times faster than method of photosystem precipitation from a solution. More specifically, PSI was immobilized on the electrode modified with gold nanoparticles (GNP). In the presence of suitable mediators, the cell generated a photocurrent of $100 \mathrm{nA} / \mathrm{cm}^{2}$ [44].

However, photobioelectrochemical elements based on the PSI monolayer were not sufficiently effective in cases when a large cross-sectional area of light absorption was required. A photobioelectrochemical cell based on multilayer structures of PSI was created in the same year [45]. The PSI complexes were platinised on the stromal side to form the multilayer structures. The platinum ions facilitated the binding of the lumenal side of PSI and the stromal side of another PSI complex that resulted in the electrically connected multilayer. The first PSI monolayer was attached to the gold surface through the bonds between the cysteine's thiol groups of the mutant PSI and the gold atoms. Then, the next layer was formed through the connection between the photosystem donor side of the next layer and the platinum atoms (Fig. 6b). The devices developed on the basis of the two and three layers generated photovoltage outputs of 0.330 and $0.386 \mathrm{~V}$, respectively [45]. Hereafter, the investigations of solar cells based on multilayer structures of PSI were continued. Method suggested by Ciesielski et al. [46] did not require the use of photosystems isolated from mutated cyanobacteria, nor the use 
of a high vacuum, so it was more economical and less time-consuming. In their study, a plate of gold (thickness of about $125 \mathrm{~nm}$ ) immobilized on a silicon substrate served as cathode and a working surface of transparent plastic plate coated with lead oxide doped with indium served as anode of the photoelement, respectively. A cavity between them was half-filled with an electrolyte composed of $5 \mathrm{mM}$ 2,6-dichlorphenolindophenol, $100 \mathrm{mM}$ ascorbic acid (Asc), and $100 \mathrm{mM} \mathrm{NaCl}$ in $5 \mathrm{mM}$ phosphate buffer at $\mathrm{pH}$ 7.0. In the other half, there was a buffer solution containing PSI complexes (about $9 \mu \mathrm{M})$, Triton-X100 $(0.05 \% \mathrm{w} / \mathrm{v}), 0.14 \mathrm{M}$ in $0.2 \mathrm{M}$ $\mathrm{NaH}_{2} \mathrm{PO}_{4}$ at $\mathrm{pH}$ 7.0. The PSI complexes were precipitated on a gold electrode for seven days. As a result, a multilayer of the PSI complexes with a thickness of 1-2 $\mu \mathrm{m}$ was obtained. The obtained solar cell generated a photocurrent at a density of about $2 \mathrm{~mA} / \mathrm{cm}^{2}$ under illumination by a standard light intensity (clear sky at noon). The device demonstrated a considerable stability and retained activity under ambient conditions for at least 280 days [46].

According to the review of the recent advances in photosynthetic energy conversion made by Sekar and Ramasamy [2], to the present day the highest current density of $362 \mathrm{~mA} / \mathrm{cm}^{2}$ and the energy flux density of $81 \mathrm{mkW} / \mathrm{cm}^{2}$ using PSI were obtained by Mershin et al. [47]. In their work, they compared the efficiency of solar cells with two different semiconductor substrates: nanocrystalline titanium dioxide $\mathrm{TiO}_{2}$ and nanowires of zinc oxide ( $\mathrm{ZnO}$ ) (Fig. 7). The measurements were carried out under normal sunlight. The PSI complexes were adsorbed on each of these two substrates. Stability of the isolated PSI complexes was increased by the treatment with surfactant Ac-AAAAAAK- $\mathrm{NH}_{2}$ - a sequence of six alanines and one lysine $\left(\mathrm{A}_{6} \mathrm{~K}\right)$. This also promoted the selective adsorption of the PSI on the substrates and increased the absorption of light. Such approach improved the photovoltaic performance. In this artificial system, cobalt electrolyte performed the role of plastocyanine, and ferredoxin was replaced by nanocrystalline $\mathrm{TiO}_{2}$, or nanofiber $\mathrm{ZnO}$ [47]. Overall, PSI is a good photobiocatalyst, but it has several disadvantages as a photosensitizer. First, the process of the complex isolation is more laborious compared with the isolation of thylakoid membranes. Second, the isolated PSI complex is less stable. Third, for getting a continuous electron transfer to $\mathrm{P}_{700}$, $\mathrm{RC}$ requires an external electron donor with a redox potential approximately equal to the redox potential of plastocyanin. Thus, the photosystem depends on other electron sources.

\subsection{Photosystem II as photobiocatalyst}

The main advantage of PSII against PSI is the fact that water is the electron source required to activate the electron transfer, and it is abundant in the environment [2]. Unlike the PSI, which requires an electron donor, PSII has an internal oxygen-evolving complex, also known as water-splitting complex. Thus, PSII depends on the availability of water and light. Here, electrons from $\mathrm{P}_{680}$ are transferred to pheophytin, then to plastoquinone and further to the other ETC components [8]. There are two major rate-limiting steps in this process: reduction of plastoquinone in QB-site by two electrons from plastoquinone in QA-site and diffusion of the double reduced quinone $\left(\mathrm{PQH}_{2}\right)$ inside membrane [8]. Therefore, it is assumed that the water oxidation in PSII should be accelerated if electrons from QA-site could be efficiently transferred to an external electron acceptor [48]. Thus, in order for the electrons from PSII to be transferred onto the electrode, the complex should come in contact with the surface of the 


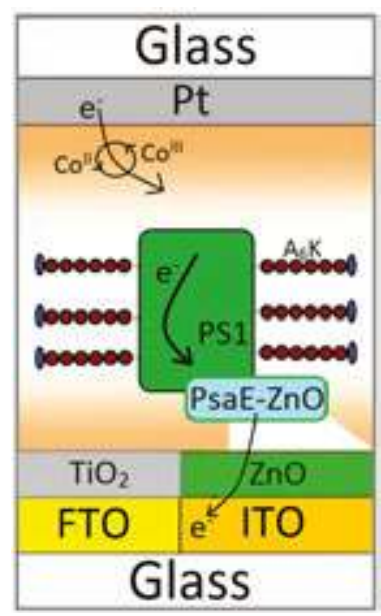

Figure 7 Schematic presentation of two Mershin's cells with zinc oxide and titanium dioxide. FTO - a layer of fluorine doped with tin oxide, ITO - a layer of indium doped with tin oxide, and PsaE-ZnO - mutant subunit (adapted from $[20,47])$.

electrode, or the electron transfer should be carried out by a mediator. In fact, it is difficult to achieve direct electron transfer from the PSII to the electrode due to the deep localization of the Pheo-PQ site inside the PSII [38].

For the creation of efficient solar cell based on PSII, it is important to improve its stability and increase electron transport efficiency. To achieve that, Vittadello et al. [49] reported the application of histidine-tagged protein complex of PSII from Synechococcus elongatus covalently bound to a gold electrode treated with $\mathrm{Ni}^{2+}$-nitrilotriacetic acid $\left(\mathrm{Ni}^{2+}-\mathrm{NTA}\right)$. The current density of the resulting photobioelectrochemical cell has reached $43 \mathrm{mkA} / \mathrm{cm}^{2}$ [49]. On the other hand, while the photochemical energy conversion efficiency of the freshly isolated PSII was 0.7, the same parameter for the PSII immobilized on gold was 0.53 . This clearly indicated that the PSII complexes were photochemically stable even after immobilization [49].

Utilization of osmium-containing redox polymer based on poly-1-vinylimidazole is also an effective immobilization method, which could help maintain the stability as well as enhance the coating degree of the electrode by the PSII complexes (Fig. 8a) [38]. The polymer works both as an immobilization matrix and a mediator. This kind of system could facilitate the electron transfer from the PSII complex to the electrode. The correct orientation of the immobilized complex could also support the electron transfer. Recently, Noji et al. [50] developed a nanodevice for the artificial water decomposition controlled by light, using a conjugate of PSIIGNP. The core of the PSII complex comprising a histidine tag on the C-terminus of CP47 protein was immobilized on a GNP by $\mathrm{Ni}^{2+}$-NTA (Fig. 8b). In this work, the diameter of GNPs was about $20 \mathrm{~nm}$, and GNPs could bind four or five PSII complexes. The efficiency of oxygen evolution by the developed PSII-GNP was comparable to that of the unbound PSII [50]. 
Israeli scientists developed the photocell on the basis of bacterial PSII complexes isolated from the thermophilic cyanobacterium Mastigocladus laminosus. The photoanode consisting of a matrix of 2-mercapto-1,4-benzoquinone was electro-polymerized on the gold surface. Then, PSII complexes were immobilized on this surface. The anode was electrically connected to the cathode by bilirubin oxidase/carbon nanotubes (BOD/CNT). It is claimed that photo-induced quinone-mediated electron transfer led to the generation of photocurrent with an output power of $0.1 \mathrm{~W}$ [37].
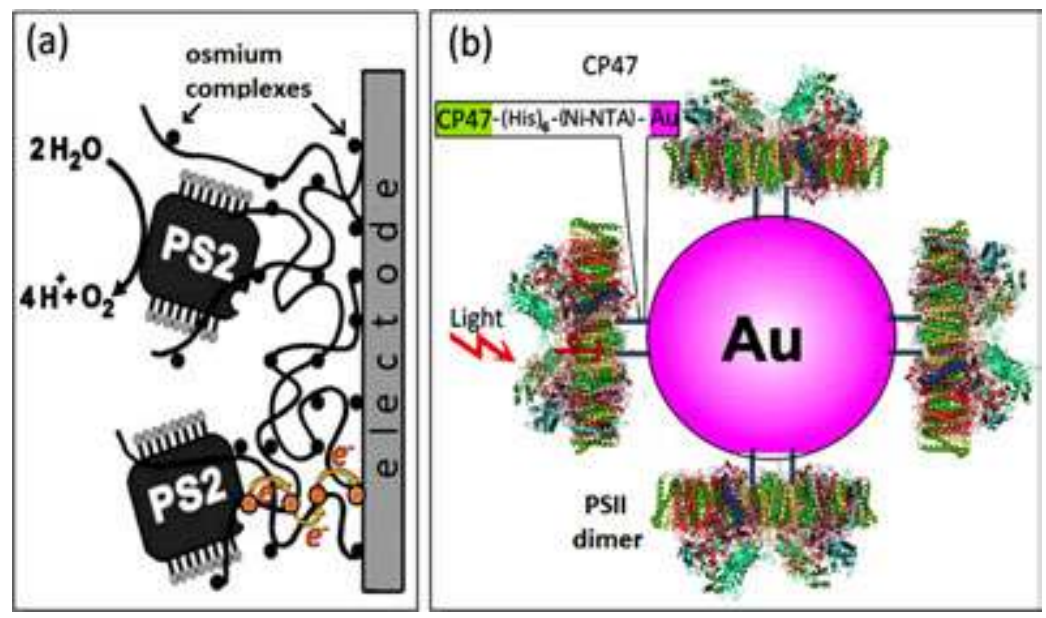

Figure 8 Models used for immobilizing photosystem II on the electrode. a) PSII associated with an osmium redox polymer containing a mediator network (adapted from [20,38]). Yellow arrows depict the electron transfer pathway by a hopping mechanism. b) Connection of PSII with gold nanoparticle through histidine tag with $\mathrm{Ni}^{2+}$-nitrilotriacetic acid $\left(\mathrm{Ni}^{2+}\right.$-NTA) attached to the C-terminus of the CP47 protein (adapted from [20, 50]).

Special protective compounds located inside the chloroplast protect highly sensitive photosystems (PSI and PSII) from photoinhibition [2]. It is evident that the stability of isolated photosystems will be impaired after their isolation from native environments. It should be noted that isolated PSII is less stable compared to PSI. Thus, photocurrent of higher density could be achieved in cells using PSI complexes [20].

\subsection{The bacterial cell as photobiocatalyst}

Photocells with isolated photosynthetic structures such as thylakoids, PSI and PSII suffer from significant disadvantages. The components of these cells are relatively unstable; they have a short running time and require labour-consuming laboratory procedures such as isolation/ purification. These limitations could be overcome if whole cells of photosynthetic microorganisms were used as a biocatalyst and/or sensitizer. In the past few years, some studies have been conducted to construct a photosynthetic microbial fuel cell (PMFC) based on whole cells of photosynthetic organisms such as cyanobacteria [2]. In the anode chamber of PMFCs, there are photosynthetic organisms that are able to oxidize water using light. PMFC requires only sunlight and water for the functioning, whereas traditional MFCs based on bacteria, for 
example, Gejbacter and Shewanella, require organic carbon sources such as glucose/lactate, and they produce $\mathrm{CO}_{2}$ as final product. Figure 9 shows the general scheme of the combined cell.

Various cyanobacteria were used in the most effective PMFCs [51-53]. In particular, the ability of the cyanobacteria Nostoc sp. in generating a photocurrent was investigated using various electrochemical methods. In a recent investigation, the mechanism of direct electron transfer from ETC of Nostoc to electrode was studied using the site-specific photosynthetic inhibitors (Fig. 1) [54]. It was shown that the solar cell with Nostoc immobilized on the MWCNT-modified carbon electrode as an anode and laccase/MWCNT-modified cathode (Fig. 5c) generated a current density of $25 \mathrm{~mA} / \mathrm{cm}^{2}$, while the maximum energy flux density achieved without mediators was only at $3.5 \mathrm{~mW} / \mathrm{cm}^{2}$ (Fig. $5 \mathrm{~d}$ ). In comparison, the cell based on thylakoids generated a maximum current density of $10 \mathrm{~mA} / \mathrm{cm}^{2}$ (Fig. 5a), and the maximum energy flux density achieved without mediators was of $5 \mathrm{~mW} / \mathrm{cm}^{2}$ (Fig. $5 \mathrm{~b}$ ). Overall, the maximum current density from the solar element based on the native photosynthetic cells was higher than that from the photoelement based on thylakoids.

One of the main advantages of cyanobacteria compared with individual components of the photosynthetic apparatus is that they are considerably less susceptible to dehydration. Currently, the power that could be generated by PMFCs is less than that achieved by the biofuel cell [2]. However, many of their advantages such as simplicity of operation, the utilization of available substrates, for example, water, as well as stress-resistance of PMFCs in comparison with the other biofuel cells mark them as promising solar cell structure for the future.
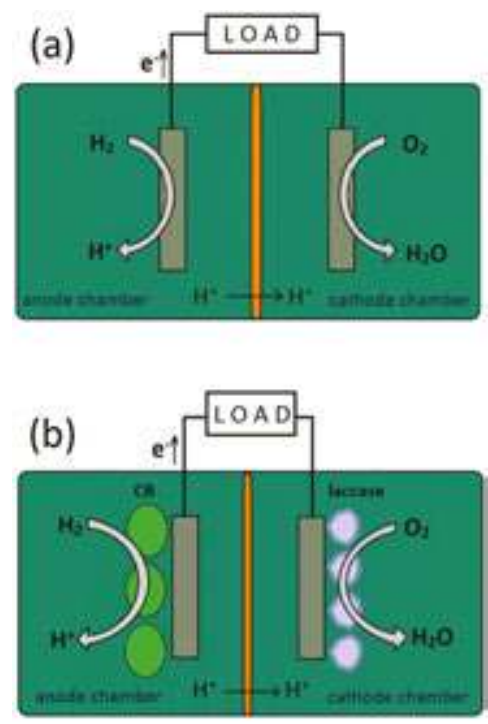

Figure 9 Schematic representation of the different forms of fuel cells: a) hydrogen fuel cell with a platinum catalyst on the anode and the cathode and b) photobioelectrochemical cell based on cyanobacterial cell (CB) on the anode and laccase enzyme on the cathode (adapted from $[2,20]$ ). 


\section{Improving the efficiency of solar cells}

\subsection{The redox-active components: changing the direction of the electron flow}

Various redox-active components accept electrons from specific sites of ETC in accordance with their redox potential. Redox active sites of metalloproteins are usually hidden inside the PSII complex [38]. Therefore, the electron transfer from immobilized photosystems onto the electrode may be limited. This limitation could be overcome by redirecting the electrons from the inner part of the protein to the surface [2]. For instance, Larom et al. [55] successfully used an artificial mediator to redirect electrons from QA-site to an artificial acceptor at a distance of about $1.3 \mathrm{~nm}$ from the stromal side of the membrane. This change in the direction of electron flow together with additional blocking of QB-site has reduced oxidative damages at the expense of reducing the time of the intermediate electron transfer at the QA/QB stage. In another study, Sekar et al. [54] used whole cells of cyanobacteria as photobiocatalysts in a solar cell. They achieved a power density of about $10 \mu \mathrm{W} / \mathrm{cm}^{2}$ by adding 1,4-benzoquinone (BQ) as a mediator. It was three times higher in comparison with power density of photoelements without a mediator using the systems Nostoc/MWCNT and laccase/MWCNT. Since both BQ and PQ have the similar structure, this addition facilitated electron transfer from the PSII to the MWCNT [54]. Previously, mediators such as BQ, 2,6-dimethyl-1-benzoquinone (DMBIB) and 2-hydroxy-1,4-naphthoquinone (HNQ) have been also used for accepting the electrons from the cyanobacterial photosynthetic ETC [51, 52].

\subsection{Bioengineering of photosynthetic RCs}

Primary processes of photosynthesis have a high quantum yield reaching almost $100 \%$, but the energy storage efficiency can reach about $27 \%$ under ideal conditions, and much less under non-ideal ones [56]. This value is comparable to the efficiency of the modern silicon-based solar panels operating with an efficiency of approximately $20 \%$. It is notable that some laboratory models have demonstrated an efficiency of $40 \%[2,7,21]$. Moreover, the photosynthetic pigments usually absorb light only from the visible region of the spectrum (from 400 to 700 $\mathrm{nm}$ ) [7] unlike photovoltaic cells that are capable of absorbing the light from ultraviolet and near infra-red regions as well. Thus, photosynthetic organisms utilize only about a half of the incident solar energy. Nevertheless, photosynthetic efficiency can be improved by expanding the region of photosynthetic absorption using bioengineering techniques. Since two photosystems used in photosynthesis absorb light under the same conditions, the variation of absorbance could increase the efficiency [20]. This approach may be performed using photoelements based on RC containing far-red and infra-red absorbing pigments similar to bacteriochlorophyll that absorbs light in the region up to $900 \mathrm{~nm}$ [57] or Chl $d$ or Chl $f$ capable of absorbing light in the region of 400-750 nm [21]. As a result, the absorption region may be significantly increased. 


\subsection{Biomimetics}

Biomimetic approach is aimed to construct an artificial systems mimicing the natural photosynthesis for the production of electricity or hydrogen. Synthetic sensitizers and catalysts are considered as a suitable alternative to unstable native systems. As a first-line strategy, porphyrins, phthalocyanines and their metal complexes that absorb light in the same optical region as the native chlorophyll molecules are regarded as such synthetic RCs. Covalently linked cyclic porphyrins are more durable, but they are difficult to synthesize [58]. Noncovalently associated porphyrins easily degrade due to their sensitivity to changing environmental conditions [59]. The advantages of utilizing the porphyrin structures include stability of the RCs and accessibility compared to synthetic products, while their disadvantage is the short lifetime in their excited state. Polypyridines containing transition metals have a longer lifetime in their high energy excited states [60]. Nevertheless, they generally require more expensive metals [53]. It should be noted that the biomimetic-based semiconductor materials mimicking the oxygen-evolved complex were designed to create energy devices during the early 1970s [61].

\section{The key challenges in photosystem-based solar cell development}

\subsection{Methods of immobilization and orientation of biocatalysts}

It is necessary to immobilize photoactive molecules on a conductive substrate for the optimum functioning of a solar cell. Most of these cells require peptides for immobilization of pigments on the electrode surface. Another important question is the correct orientation of pigment molecules. The studies conducted at Stanford [62] were focused on the orientation of photosynthetic RCs towards the electrode surface. According to this construction, a poly-histidine tag was attached to the C-terminus of the M-subunit of the Rhodobacter sphaeroides RC. With the help of the tag, the construction was immobilized on a gold electrode containing selfassembling layer of alkanethiols with $\mathrm{Ni}^{2+}$-NTA as a head part. It has been experimentally shown that the proximity of RCs to the electrode is important for the cell effective operation [63].

Many techniques were used for immobilization of photosynthetic complexes, including bioelectrocatalystic self-assembling monolayers (bio-SAMs) [45, 47, 63, 64]; $\mathrm{Ni}^{2+}$-NTA attached to poly-histidine tagged PSI complexes (Fig. 6a) [24, 54]; the redox-active hydrogels [38] (Fig. 8a) and fixation on CNTs by means of molecular binding reagents [32]. Each of these techniques provides various beneficial properties, including the increase of the electrode surface area, the rise of the electron transfer rate between the electrode and photobiocatalyst and/or orientation of specific enzymes on the electrode. Unfortunately, enzyme immobilization reduces their activity in comparison with their native state. Therefore, the enzyme activity should be retained for a long time with the help of correct immobilization methods. In a study conducted by Meunier et al. [65], thylakoids were adsorbed on a silicon matrix, thereby the stability of the native thylakoid suspension increased and it remained active for 30 days. Immobilization should provide an optimum rate of electron transfer from the protein to the 
electrode, with minimal resistance. This can be achieved by correct orientation of proteins on the electrode surface or by the usage of intermediate carriers. Many investigations have shown that the correct orientation of a photosystem on the electrode results in an improved electron transport [45]. In many studies, the correct orientation of the photosystems provides specific binding of a histidine-tagged protein complex with $\mathrm{Ni}^{2+}$-NTA molecule anchored to a gold electrode [24, 50]. Badura et al. [38] used the osmium-containing polymer of polyvinylimidazole as modified electrode acting as both an immobilizing agent and an electron acceptor for the PSII complex (Fig. 8a). Binding of sensitizer with redox polymer is rather interesting way of sensitizer immobilization. Due to that, an electron transfer between neighbouring redox centres covalently bound to the polymer backbone is possible by means of a hopping mechanism. Thus, there could be the shuttling of electrons from a reactive site within a redox protein towards an electrode surface. Several parameters determine the rate of electron transfer: the polymer backbone composition (flexibility, swelling behaviour, and amount of cross-linking), the distance between the polymer-bound redox centres and potential of the mediator. Hence, the properties of the redox polymer can be adapted to find an appropriate redox polymer for a specific application. In these modified systems, immobilized PSII were capable of generating a current density of $45 \mathrm{~mA} / \mathrm{cm}^{2}$ at light intensity of $2.65 \mathrm{~mW} / \mathrm{cm}^{2}$ (maximum wavelength at $675 \mathrm{~nm})[38]$.

\subsection{The stability of the isolated proteins}

The main problem of the usage of isolated proteins as photosensitizers in photovoltaic cells is their extremely low stability. Photoinhibition of photosystems is the main reason for protein destruction, especially in case of the PSII. Caused by an excessive amount of radiation, photoinhibition may damage the photosynthetic apparatus and hence destroy the chloroplast proteins. Photosystems are provided with some protective mechanisms in vivo [2]. However, once the proteins are isolated, natural self-healing mechanisms do not work. Thus, isolated proteins are more susceptible to damage and have a short lifetime. There is one of the methods to stabilize the photosynthetic complexes through the simulation of the natural states of proteins. Surfactant peptides can be used to imitate the lipid membrane naturally stabilizing photosynthetic complexes. Such surfactants are designed as molecular nanomaterial to study the membrane protein's stability [47]. It consists of hydrophilic amino acids (aspartate or lysine) as the head of the chain and hydrophobic amino acids (alanine) as the tail. For the stabilization of the photosynthetic complex during the construction of a solid electrical device, Das et al. [24] used the peptides $A_{6} K$ and $V_{6} D$, a sequence of six valines and one aspartic acid (VVVVVVD), as cationic and anionic surfactant peptides, respectively. They showed a shortcircuit current density of $0.12 \mathrm{~mA} / \mathrm{cm}^{2}$ at the excitation light intensity of $10 \mathrm{~W} / \mathrm{cm}^{2}$ with a wavelength of $808 \mathrm{~nm}$. Presumably, this direction is promising.

\subsection{Increase of surface area}

The increase of the electrode surface area is a method conventionally used to improve the efficiency of functioning solar cells. In many cases, the electrode itself is originally flat, and changes of its geometry can destroy its structure. However, the electrode can be modified via 
nanomaterials, which could increase the real surface area due to the formation of nanostructures with non-planar topology on the electrode surface. In this case, the working electrode area is larger than the area of the initial flat surface, and it can absorb more pigment molecules. In their study, Mershin et al. [47] compared two different forms of electrode modification using nanocrystals of titanium dioxide and zinc oxide nanowires (Fig. 7). In contrast with the flat electrodes of the same size, the electrodes using $\mathrm{TiO}_{2}$ and $\mathrm{ZnO}$ had 200 and 30 times larger active areas, respectively. The results of this study demonstrated that the samples based on $\mathrm{ZnO}$ were less effective due to the smaller coefficient of roughness. On the other hand, $\mathrm{ZnO}$ was found to be more conductive and less expensive in comparison with the $\mathrm{TiO}_{2}$ [47].

The cells of that construction used in Mershin's experiments are worth discussing in more detail. It is a stable and acknowledged design of solar cells. These cells are called dye-sensitized solar cells (DSSC) or Grätzel cell named after the one of its inventors, Michael Grätzel [21]. The advantage of such cells over the others is exactly in the usage of mesoscopic material as a substrate for photoactivator. The mesoscopic material is the material with a complicated inner structure represented by interpenetrating network of inorganic or organic semiconductor particles of mesoscopic size $(2-50 \mathrm{~nm})$ forming connections of very high contact area [4]. The structure of DSSC can be described as follows (Fig. 10). The main components of DSSC are two flat glass electrodes. Each of them has one conductive side. The conductive side is provided by application of thin layer of indium tin oxide (ITO) or fluorine tin oxide (FTO). The layer of mesoscopic semiconductive material is deposited on the one of the electrodes. Also, there is a monolayer of the dye attached to the surface of the nanocrystalline film. Photoexcitation of the dye results in the injection of an electron into the conduction band of the semiconductor. For the original state of the dye to be subsequently restored, there is the electrolyte, usually an organic solution containing redox system, such as the iodide/triiodide couple. It donates an electron to the dye. Timely regeneration of the sensitizer by iodide retards the recapture of the conduction band electron by the oxidized dye. The reduction of triiodide at the counter electrode regenerates the iodide, and the circuit is completed via electron migration through the external load. The mesoscopic oxide films are made of networks of thin crystals of a few nanometers. The components mostly preferred are the oxides such as $\mathrm{TiO}_{2}, \mathrm{ZnO}, \mathrm{SnO}_{2}$, $\mathrm{Nb}_{2} \mathrm{O}_{5}$ or chalcogenides such as CdSe. They are bound inside and this allows the electron conduction to occur. Generally, the size of $\mathrm{TiO}_{2}$ particles is about $20 \mathrm{~nm}$ [4]. Before Grätzel cells, many cells were designed by the application of photosensitizer on flat electrode. In case of flat topology solar cells, a low density of pigments is one of low efficiency reasons. In DSSC, there are several advantages of nanocrystalline structure of semiconducting oxide (usually $\mathrm{TiO}_{2}$ ) used for sensitizer support [4]:

1. It enables the effective capture of light by the surface with sensitizer absorbed. On the flat surface, a monolayer absorbs less than a few percent of light as it covers an area approximately two order of magnitude larger than its optical cross-section [4]. The use of multilayered sensitizer would not solve this problem as molecules only in contact with semiconductor could excite it; the others act like filter. Significant increase of interface enhances absorption and leads to thousand-fold increase of photocurrent in comparison with flat surface DSSC. 
2. Nanocrystals of $\mathrm{TiO}_{2}$ should not be somehow doped to have the conductivity. Injection of one electron from sensitizer to $\mathrm{TiO}_{2}$ particle is enough for titanium dioxide to get its conducting state. This photo-induced conductivity allows gathering the electron without any significant ohmic losses. In contrast, it is necessary for compact semiconductive films to be n-doped so that semiconductor could conduct the current. In this case, the energy transport from excited sensitizer to conducting band of semiconductor will inevitably decrease the coefficient of efficiency.

3. Size of $\mathrm{TiO}_{2}$ particles allows effectively screening electrons from the electrolyte or hole conductor present in pores. As a result, photocurrent is not declined by a repulse between electrons diffusing through the particle network.

Ruthenium dyes are used as sensitizers in most studies connected with Grätzel cells [4, 21]. But isolated components of photosynthetic apparatus as dyes are also quite attractive since ruthenium dyes are rather expensive. Some studies including Mershin's investigations offer significant possibilities in this area.

As it has already been shown, the mesoscopic materials cannot be the only way to increase an active surface area of solar cell. In fuel cells of another kind, nanotextured surfaces are also used to increase the amount of absorbed dye molecules. As the technique for creating nanowires, nanotubes and other structures for carbon materials is quite well developed, carbon is rather attractive as a material for the creation of such surfaces. These approaches include the usage of GNPs [50], nanoporous gold electrodes [46] and redox hydrogels [38].

\subsection{Direct or mediated transfer of electrons}

Another way to achieve the maximum current density in the cells based on photosynthetic sensitizers is to create a system that carries out direct electron transfer from photosystem to electrode without using a mediator. As was mentioned earlier, the mediators have lower redox potential required for the efficient electron transfer compared to the native electron source. If the electrons are transferred to the mediator, they lose some part of their energy in contrast to transfer from the real source. The distance between the redox site and the electrode should also be minimized in order to ensure efficient transfer of electrons. The difficulty in ensuring continuous contact between the electron source and the electrode is the main disadvantage of direct electron transfer.

Furukawa et al. used polyaniline as an electronic catalyst instead of mediators to develop a photosynthetic biofuel cell [66]. Polyaniline has a good electrical conductivity; it is compatible with the photosystem. Due to its nanostructure, polyaniline also increases the surface area. During their experiment, they managed to achieve a good efficiency of the developed cell: peak current density was about $150 \mathrm{~mA} / \mathrm{cm}^{2}$ and power density was measured at $5.3 \mathrm{mkW} / \mathrm{cm}^{2}$. According to the study conducted by Sekar et al. [54], MWCNTs were successfully used for direct electron transfer, both in isolated spinach thylakoids and cyanobacteria Nostoc sp. 


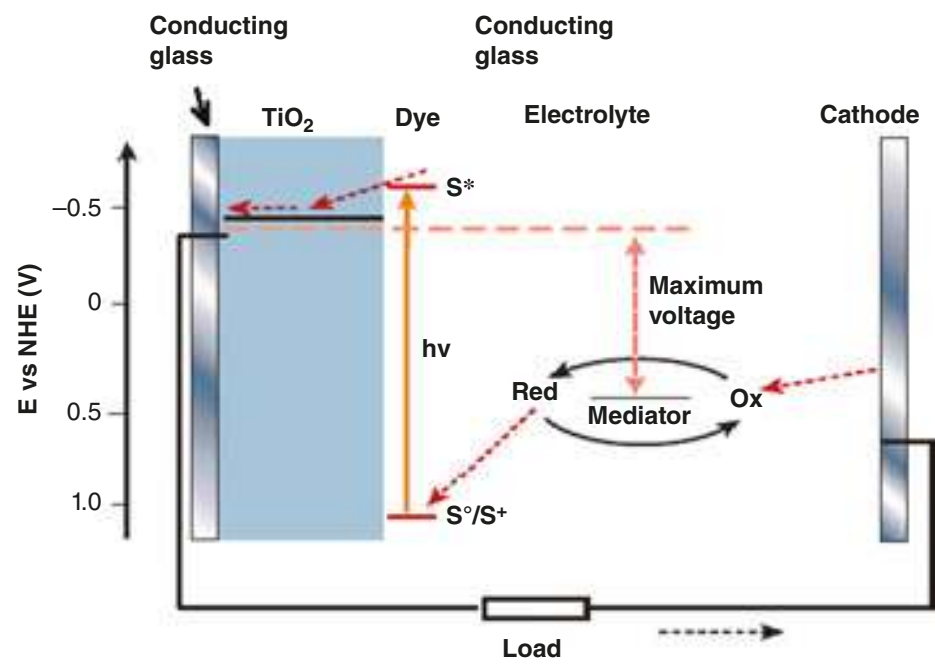

Figure 10 Scheme of operation of the dye-sensitized solar cell. The photoanode, made of a mesoporous dye-sensitized semiconductor, receives electrons from the photo-excited dye which is thereby oxidized, and which in turn oxidizes the mediator, a redox species dissolved in the electrolyte. The mediator is regenerated by reduction at the cathode by the electrons circulated through the external circuit. Energy levels are measured in relation to normal hydrogen electrode (NHE). S - ground state of dye molecule. $S^{+}-$its oxidized state, $S^{*}$ - its exited state (adapted from [21]).

\subsection{Extension of the spectral range of the light absorption by photosystems}

Previous four problems were closely linked: stability of isolated complexes directly depends on the way of its immobilization on electrode. For creating electrodes with complex surface, it is necessary to consider the ability of the surface to adsorb sensitizer molecules. In their experiments, Badura et al. [38] have been solving all these four problems at once. $\mathrm{Ni}^{2+}-\mathrm{NTA}$ and 6-His tag are both mediators of electron transport and a means of photosystem attachment on electrode surface. Immobilization, dye stability, working surface area and mediation of electron transport are connected with 'dye/electrode' contact. The increase of the spectral absorption region is the matter that is connected only with sensitizer. Extension of the spectral range of the light absorption is possible using Chl $d$ or $f[15,21,67-70]$. Though the creation of artificial solar cells based on these chlorophylls is still at the early stages of its development. Overall, designing of solar cells using these chlorophylls seems to be quite promising.

\section{Conclusion}

Researchers in the area of artificial photosynthesis have focused on the development of total inorganic and hybrid semi-natural systems $[71,72]$ that could effectively produce a sustainable energy from sunlight without requiring external fuels. These systems should have a high quantum yield and generate energy fluxes of high density to satisfy the energy requirements. 
The more we learn about the nature, the closer we come to the creation of the efficient energy solar cells using the components of photosynthetic apparatus. The usage of systems imitating the photosynthetic apparatus and the elements of photosynthetic systems in current energy generators and fuel cells is a quite promising direction $[72,73]$. However, the biophotovoltaics requires a lot of changes and improvements to be widely used.

\section{Acknowledgements}

The work was supported by the Russian Science Foundation №14-14-00039 (to S.I.A.) and by the grant-in-aid for Specially Promoted Research No. 24000018 (J.-R.S.) from JSPS, MEXT, Japan.

\section{Author details}

Roman A. Voloshin ${ }^{1 *}$, Margarita V. Rodionova ${ }^{1}$, Sergey K. Zharmukhamedov ${ }^{2}$, Harvey J.M. Hou ${ }^{3}$, Jian-Ren Shen ${ }^{4}$ and Suleyman I. Allakhverdiev ${ }^{1,2,5^{*}}$

${ }^{*}$ Address all correspondence to: voloshinra@gmail.com

*Address all correspondence to: suleyman.allakhverdiev@gmail.com

1 Controlled Photobiosynthesis Laboratory, Institute of Plant Physiology, Russian Academy of Sciences, Moscow, Russia

2 Institute of Basic Biological Problems, Russian Academy of Sciences, Pushchino, Moscow, Russia

3 Department of Physical Sciences, Alabama State University, Montgomery, USA

4 Photosynthesis Research Center, Graduate School of Natural Science and Technology/ Faculty of Science, Okayama University, Japan

5 Department of Plant Physiology, Faculty of Biology, M.V. Lomonosov Moscow State University, Moscow, Russia

\section{References}

[1] Ort D.R., Merchant S.S., Alric J., Barkan A., Blankenship R.E., Bock R., Croce R., Hanson M.R., Hibberd J.M., Long S.P., Moore T.A., Moroney J., Niyogi K.K., Parry M.A.J., Peralta-Yahya P.P., Prince R.C., Redding K.E., Spalding M.H., van Wijk K.J., Vermaas 
W.F.J., von Caemmerer S., Weber A.P.M., Yeates T.O., Yuan J.S., and Zhu X.G. Redesigning photosynthesis to sustainably meet global food and bioenergy demand. Proceedings of the National Academy of Sciences of the United States of America. 2015;112(28): 8529-8536.

[2] Sekar N., Ramasamy R. Recent advances in photosynthetic energy. Journal of Photochemistry and Photobiology C: Photochemistry. 2015;22:19-33.

[3] Lewis N.S., Nocera D.G. Powering the planet: Chemical challenges in solar energy utilization. Proceedings of the National Academy of Sciences of the United States of America. 2006;103(43):15729-15735.

[4] Grätzel M. Photovoltaic and photoelectrochemical conversion of solar energy. Philosophical Transactions of the Royal Society. 2007;365:993-1005.

[5] Mazor Y., Borovikova A., Nelson N. The structure of plant photosystem I supercomplex at 2.8 Å resolution. eLife. 2015;4. DOI: 10.7554/eLife.07433.

[6] Suga M., Akita F., Hirata K., Ueno G., Murakami H., Nakajima Y., Shimizu T., Yamashita K., Yamamoto M., Ago H., ShShen J.-R. Native structure of photosystem II at 1.95 $\AA$ resolution viewed by femtosecond X-ray pulses. Nature. 2015;517: 99-103. DOI: 10.1038/nature13991.

[7] Blankenship R.E., Tiede D.M., Barber J., Brudvig G.W., Fleming G., Ghirardi M.R., Gunner M., Junge W., Kramer D.M., Melis A., Moore T.A., Moser C.C., Nocera D.G., Nozik A.J., Ort D.R., Parson W.W., Prince R.C., Sayre R.T. Comparing photosynthetic and photovoltaic efficiencies and recognizing the potential for improvement. Science. 2011;332:805-809.

[8] Blankenship R.E., editors. Molecular Mechanisms of Photosynthesis. Oxford: Blackwell Science; 2002. 321 p. DOI: 10.1002/9780470758472.

[9] Blankenship R.E. Early evolution of photosynthesis. Plant Physiology. 2010;154:434-438.

[10] Blankenship R.E., Hartman H. The origin and evolution of oxygenic photosynthesis. Trends in Biochemical Sciences. 1998;23:94-97.

[11] Nelson N., Yocum C.F. Structure and function of photosystem I and II. Annual Review of Plant Biology. 2006;57:521-565.

[12] Andralojc J., Harris D.A. The chloroplast ATP-synthase - A light regulated enzyme. Biochemical Education. 1992;20(1):44-48.

[13] Qin X., Suga M., Kuang T., Shen J.-R. Structural basis for energy transfer pathways in the plant PSI-LHCI supercomplex. Science. 2015;348(6238):989-995.

[14] Scheer H. An overview of chlorophylls and bacteriochlorophylls: Biochemistry, biophysics, functions and applications. In: Grimm B., Porra R.J., Rüdiger W., Scheer H, editors. Chlorophylls and Bacteriochlorophylls: Biochemistry, Biophysics, Functions and Applications. Dordrecht: Springer; 2006. pp. 4-11. 
[15] Loughlin P., Lin Y., Chen M. Chlorophyll d and Acaryochloris marina: Current status. Photosynthesis Research. 2013;116(2-3):277-293.

[16] Sandman G. Evolution of carotenoid desaturation: The complication of a simple pathway. Archives of Biochemistry and Biophysics. 2009;483:169-174.

[17] Tomo T., Akimoto S., Tsuchiya T., Fukuya M., Tanaka K., Mimuro M. Isolation and spectral characterization of photosystem II reaction center from Synechocystis sp. PCC 6803. Photosynthesis Research. 2008;98:293-302.

[18] Tomo T., Shinoda T., Chen M., Allakhverdiev S.I., Akimoto S. Energy transfer processes in chlorophyll f-containing cyanobacteria using time-resolved fluorescence spectroscopy on intact cells. Biochimica et Biophysica Acta . 2014;1837:1484-1489.

[19] Blankenship R.E., Chen M. Spectral expansion and antenna reduction can enhance photosynthesis for energy production. Current Opinion in Chemical Biology. 2013;17:457-461.

[20] Voloshin R.A., Kreslavski V.D., Zharmukhamedov S.K., Bedbenov V.S., Ramakrishna S., Allakhverdiev S.I. Photoelectrochemical cells based on photosynthetic systems: A review. Biofuel Research Journal. 2015;6:227-235.

[21] Grätzel M. Photoelectrochemical cells. Nature. 2001;414:338-344.

[22] Lubner C.E., Applegate A.M., Knörzer P., Ganago A., Bryant D.A., Happe T., Golbeck J.H. Solar hydrogen-producing bionanodevice outperforms natural photosynthesis. Proceedings of the National Academy of Sciences of the United States of America. 2011;108(52): 20988-20991.

[23] Torella J.P., Gagliardi C.J., Chen J.S., Bediako D.K., Colón B., Way J.C., Silver P.A., Nocera D.G. Efficient solar-to-fuels production from a hybrid microbial-watersplitting catalyst system. Proceedings of the National Academy of Sciences of the United States of America. 2015;112(8):2337-2342.

[24] Das R., Kiley P.J., Segal M., Norville J., Yu A.A., Wang L.Y., Trammell S. A., Reddick L. E., Kumar R., Stellacci F., Lebedev N., Schnur J., Bruce B.D., Zhang S.G., Baldo M. Integration of photosynthetic protein molecular complexes in solid-state electronic devices. Nano Letters. 2004;4:1079-1083.

[25] Gamry Instruments. DSSC: Dye Sensitized Solar Cells [Internet]. 2015 [Updated: 2015]. Available from: http://www.gamry.com/application-notes/physechem/dssc-dyesensitized-solar-cells/ [Accessed: 2015].

[26] Tel-Vered R., Willner I. Photo-bioelectrochemical cells for energy conversion, sensing, and optoelectronic applications. ChemElectroChem. 2014;1:1778-1797.

[27] Kato M., Zhang J.Z., Pau N., Reisner E. Protein film photoelectrochemistry of the water oxidation enzyme photosystem II. Chemical Society Reviews. 2014;43:6485-6497. 
[28] Lam K.B., Irwin E.F., Healy K.E., Lin L. Bioelectrocatalytic self-assembled thylakoids for micro-power and sensing applications. Sensors and Actuators B: Chemical. 2006;117:480-487.

[29] Kato M., Cardona T., Rutherford A.W., Reisner E. Photoelectrochemical water oxidation with photosystem II integrated in a mesoporous indium-tin oxide electrode. Journal of the American Chemical Society. 2012;134:8332-8335.

[30] Shah V.B., Henson W.R., Chadha T.S., Lakin G., Liu H., Blankenship R.E., Biswas P. Linker-free deposition and adhesion of photosystem I onto nanostructured $\mathrm{TiO}_{2}$ for biohybrid photoelectrochemical cells. Langmuir. 2015;31:1675-1682.

[31] LeBlanc G., Chen G., Gizzie E.A., Jennings G.K., Cliffel D.E. Enhanced photocurrents of photosystem I films on p-doped silicon. Advanced Materials. 2012;24:5959-5962.

[32] Calkins J.O., Umasankar Y., O’Neill H., Ramasamy R.P. High photoelectrochemical activity of thylakoid-carbon nanotube composites for photosynthetic energy conversion. Energy \& Environmental Science. 2013;6:1891-1900.

[33] Yehezkeli O., Wilner O.I., Tel-Vered R., Roizman-Sade D., Nechushtai R., Willner I. generation of photocurrents by bis-aniline-cross-linked Pt nanoparticle/photosystem I composites on electrodes. Journal of Physical Chemistry B. 2010;114:14383-14388.

[34] Rao K.K., Hall D.O., Vlachopoulos N., Grätzel M., Evans M.C.W., Seibert M. Photoelectrochemical responses of photosystem II particles immobilized on dye-derivatized $\mathrm{TiO}_{2}$ films. Journal of Photochemistry and Photobiology B: Biology. 1990;5:379-389.

[35] Efrati A., Tel-Vered R., Michaeli D., Nechushtai R., Willner I. Cytochrome c-coupled photosystem I and photosystem II (PSI/PSII) photo-bioelectrochemical cells. Energy $\mathcal{E}$ Environmental Science. 2013;6:2950-2956.

[36] Kothe T., Plumeré N., Badura A., Nowaczyk M.M., Guschin D.A., Rögner M., Schuhmann W. Combination of a photosystem 1-based photocathode and a photosystem 2based photoanode to a Z-scheme mimic for biophotovoltaic applications. Angewandte Chemie International Edition. 2013;52:14233-14236.

[37] Yehezkeli O., Tel-Vered R., Wasserman J., Trifonov A., Michaeli D., Nechushtai R., Willner I. Integrated photosystem II-based photo-bioelectrochemical cells. Nature Communications. 2012;742(3):1-7. DOI: 10.1038/ncomms1741.

[38] Badura A., Guschin D., Esper B., Kothe T., Neugebauer S., Schuhmann W., Rogner M. Photo-induced electron transfer between photosystem II via crosslinked redox hydrogels. Electroanalysis. 2008;20:1043-1047.

[39] Badura A., Guschin D., Kothe T., Kopczak M.J., Schuhmann W., Rogner M. Photocurrent generation by photosystem 1 integrated in crosslinked redox hydrogels. Energy $\mathcal{E}$ Environmental Science. 2011;4:2435-2440. 
[40] Carpentier R., Lemieux S., Mimeault M., Purcell M., Goetze D.C. A photoelectrochemical cell using immobilized photosynthetic membranes. Bioelectrochemistry and Bioenergetics. 1999;22:391-401.

[41] Bedford N.M., Winget G.D., Punnamaraju S., Steckl A.J. Immobilization of stable thylakoid vesicles in conductive nanofibers by electrospinning. Biomacromolecules. 2011;12:778-784.

[42] Fourmond V., Lagoutte B., Setif P., Leibl W., Demaille C. Electrochemical study of a reconstituted photosynthetic electron-transfer chain. Journal of the American Chemical Society. 2007;129:9201-9209.

[43] Frolov L., Rosenwaks Y., Carmeli C., Carmeli I. Fabrication of a photoelectronic device by direct chemical binding of the photosynthetic reaction center protein to metal surfaces. Advanced Materials. 2005;17:2434-2437. DOI: 10.1002/adma.200500295.

[44] Faulkner C.J., Lees S., Ciesielski P.N., Cliffel D.E., Jennings G.K. Rapid assembly of photosystem I monolayers on gold electrodes. Langmuir. 2008;24:8409-8412.

[45] Frolov L., Wilner O., Carmeli C., Carmeli I. Fabrication of oriented multilayers of photosystem I proteins on solid surfaces by auto-metallization. Advanced Materials. 2008;20:263-266.

[46] Ciesielski P.N., Hijazi F.M., Scott A.M., Faulkner C.J., Beard L., Emmett K., Rosenthal S.J., Cliffel D., Jennings G.K. Photosystem I - Based biohybrid photoelectrochemical cells. Bioresource Technology. 2010;101:3047-3053.

[47] Mershin A., Matsumoto K., Kaiser L., Yu D.Y., Vaughn M., Nazeeruddin M.K., Bruce B.D., Graetzel M., Zhang S.G. Self-assembled photosystem-I biophotovoltaics on nanostructured $\mathrm{TiO}_{2}$ and ZnO. Scientific Reports. 2012;234(2\}):1-7. DOI: 10.1038/ srep00234.

[48] Ulas G., Brudvig G.W. Redirecting electron transfer in photosystem II from water to redox-active metal complexes. Journal of the American Chemical Society. 2011;133:1326013263.

[49] Vittadello M., Gorbunov M.Y., Mastrogiovanni D.T., Wielunski L.S., Garfunkel E.L., Guerrero F., Kirilovsky D., Sugiura M., Rutherford A.W., Safari A., Falkowski P.G. Photoelectron generation by photosystem II core complexes tethered to gold surfaces. ChemSusChem. 2010;3:471-475.

[50] Noji T., Suzuki H., Gotoh T., Iwai M., Ikeuchi M., Tomo T., Noguchi T. Photosystem II - Gold nanoparticle conjugate as a nanodevice for the development of artificial lightdriven water-splitting systems. Journal of Physical Chemistry Letters. 2011;2:2448-2452.

[51] Yagishita T., Horigome T., Tanaka K. Effects of light, CO2 and inhibitors on the current output of biofuel cells containing the photosynthetic organism Synechococcus sp. Journal of Chemical Technology and Biotechnology. 1993;56:393-399. 
[52] Torimura M., Miki A., Wadano A., Kano K., Ikeda T. Electrochemical investigation of cyanobacteria Synechococcus sp. PCC7942-catalyzed photoreduction of exogenous quinones and photoelectrochemical oxidation of water. Journal of Electroanalytical Chemistry. 2001;496:21-28.

[53] Pisciotta J.M., Zou Y., Baskakov I.V. Light-dependent electrogenic activity of cyanobacteria. PLoS ONE. 2010;5:1-10. DOI: 10.1371/journal.pone.0010821.

[54] Sekar N., Umasankar Y., Ramasamy R.P. Photocurrent generation by immobilized cyanobacteria via direct electron transport in photo-bioelectrochemical cells. Physical Chemistry Chemical Physics. 2014;16(17):7862-7871.

[55] Larom S., Salama F., Schuster G., Adir N. Engineering of an alternative electron transfer path in photosystem II. Proceedings of the National Academy of Sciences of the United States of America. 2010;107:9650-9655.

[56] Fultz M.L., Durst R.A. Mediator compounds for the electrochemical study of biological redox systems - A compilation. Analytica Chimica Acta. 1982;140:1-18.

[57] Hanna M.C., Nozik A.J. Solar conversion efficiency of photovoltaic and photoelectrolysis cells with carrier multiplication absorbers. Journal of Applied Physics. 2006;100:1-8.

[58] Sanders J.K.M., editors. Porphyrin Handbook. New York: Academic Press; 2000.

[59] Iengo E., Zangrando E., Alessio E. Discrete supramolecular assemblies of porphyrins mediated by coordination compounds. European Journal of Inorganic Chemistry. 2003;2003:2371-2384.

[60] Krassen H., Ott S., Heberle J. In vitro hydrogen production - Using energy from the sun. Physical Chemistry Chemical Physics. 2011;13:47-57.

[61] Fujishima A., Honda K. Electrochemical photolysis of water at a semiconductor electrode. Nature. 1972;238:37-38.

[62] Goldsmith J.O., Boxer S.G. Rapid isolation of bacterial photosynthetic reaction centers with an engineered poly-histidine tag. Biochimica et Biophysica Acta. 1996;1276:171-175.

[63] Kincaid H.A., Niedringhaus T., Ciobanu M., Cliffel D.E., Jennings G.K. Entrapment of photosystem I within self-assembled films. Langmuir. 2006;22:8114-8120.

[64] Nakamura C., Hasegawa M., Yasuda Y., Miyake J. Self-assembling photosynthetic reaction centers on electrodes for current generation. Biotechnology and Applied Biochemistry. 2000;84(6):401-408.

[65] Meunier C.F., Van Cutsem P., Kwon Y.U., Su B.L. Thylakoids entrapped within porous silica gel: Towards living matter able to convert energy. Journal of Materials Chemistry. 2009;19:1535-1542. 
[66] Furukawa Y., Moriuchi T., Morishima K. Design principle and prototyping of a direct photosynthetic/metabolic biofuel cell (DPMFC). Journal of Micromechanics and Microengineering. 2006;16:220-225.

[67] Allakhverdiev S.I., Tomo T., Shimada Y., Kindo H., Nagao R., Klimov V.V., Mimuro M. Redox potential of pheophytin a in photosystem II of two cyanobacteria having the different special pair chlorophylls. Proceedings of the National Academy of Sciences of the United States of America. 2010;107:3924-3929.

[68] Chen M., Schliep M., Willows R.D., Cai Z.-L., Neilan B.A., Scheer H. A red-shifted chlorophyll. Science. 2010;329:1318-1319.

[69] Chen M., Scheer H. Extending the limit of natural photosynthesis and implications of technical light harvesting. Journal of Porphyrins and Phthalocyanines. 2013;17:1-15.

[70] Tomo T., Allakhverdiev S.I., Mimuro M. Constitution and energetics of photosystem I and photosystem II in the chlorophyll d-dominated cyanobacterium Acaryochloris marina. Journal of Photochemistry and Photobiology B: Biology. 2011; 104:333-340.

[71] Hou H.J.M., Allakhverdiev S.I., Najafpour M.M., Govindjee. Current challenges in photosynthesis: From natural to artificial. Frontiers Publishers. 2014;5:1-3.

[72] Allakhverdiev S.I., Ramakrishna S. A random walk to and through the photoelectrochemical cells based on photosynthetic systems. Biofuel Research Journal. 2015;6:222.

[73] Marshall J. Solar energy: Springtime for the artificial leaf. Nature. 2014;510:22-24. 